\title{
2008+10. Uma análise sobre as mudanças das novas tecnologias da comunicação na história recente dos desastres de Blumenau, Brasil
}

\author{
Clóvis Reis \\ Universidade Regional de Blumenau - Blumenau - SC - Brasil \\ ORCID: https://orcid.org/0000-0002-8131-9229 \\ Moisés Cardoso \\ Universidade Regional de Blumenau - Blumenau - SC - Brasil \\ ORCID: https://orcid.org/0000-0003-2447-756X \\ Yanet M. Reimondo Barrios \\ Universidade Regional de Blumenau - Blumenau - SC - Brasil \\ ORCID: https://orcid.org/0000-0002-3200-1345
}

\begin{abstract}
Resumo
Em 2008, Blumenau sofreu o maior desastre socioambiental da história. Passados dez anos da tragédia, o presente trabalho reúne algumas reflexões sobre a mudança no emprego das tecnologias de comunicação na cobertura de fenômenos semelhantes. O quadro metodológico se constitui, desde uma perspectiva de ordem qualitativa, em uma investigação bibliográfica, adotando um enfoque exploratório e descritivo. A análise centrou-se em descrever como dito processo se desenvolveu na última década, tendo em conta que a mudança dos procedimentos técnicos e políticos para a confrontação de referidos fenômenos coincide com as transformações pelas quais as tecnologias da comunicação passaram. A pesquisa contribuiu para fornecer pistas sobre o papel que jornais, emissoras de rádio e de televisão, redes sociais virtuais e aplicativos móveis exerceram em Blumenau na construção da percepção pública dos riscos, e as implicações de tais enquadramentos para a gestão dos desastres.
\end{abstract}

Palavras-chave: Desastres. Tecnologias de comunicação. Desenvolvimento. Blumenau.

$2008+10$. An analysis of the changes in the new communication technologies in the recent history of the disasters of Blumenau, Brazil

Abstract

In 2008, Blumenau suffered the greatest socio-environmental disaster in history. Ten years after the tragedy, this paper brings together some reflections on the change in the use of communication technologies in the coverage of such phenomena. The methodological framework is constituted, from a qualitative perspective, in a bibliographic investigation, 
adopting an exploratory and descriptive approach. The analysis focused on describing how this process developed in the last decade, taking into account that the change of technical and political procedures for the confrontation of such phenomena coincides with the transformations by which communication technologies have passed. The research contributed to provide clues about the role that newspapers, radio and television broadcasters, virtual social networks and mobile applications played in Blumenau in building public perceptions of risks, and the implications of such frameworks for disaster management.

Keywords: Disasters. Communication technologies. Development. Blumenau.

\section{8 + 10. Un análisis sobre los cambios de las nuevas tecnologías de la comunicación en la historia reciente de los desastres de Blumenau, Brasil}

\section{Resumen}

En 2008, Blumenau sufrió el mayor desastre socioambiental de su historia. Pasados diez años de la tragedia, el presente trabajo reúne algunas reflexiones sobre el cambio en el empleo de las tecnologías de comunicación en la cobertura de fenómenos semejantes. El marco metodológico se constituye, desde una perspectiva cualitativa, en una investigación bibliográfica, adoptando un enfoque exploratorio y descriptivo. El análisis se centró en describir cómo dicho proceso se desarrolló en la última década, teniendo en cuenta que el cambio de los procedimientos técnicos y políticos para la confrontación de dichos fenómenos coincide con las transformaciones por las cuales las tecnologías de la comunicación pasaron. La investigación contribuyó a proporcionar pistas sobre el papel que periódicos, emisoras de radio y televisión, redes sociales virtuales y aplicaciones móviles ejercieron en Blumenau en la construcción de la percepción pública de los riesgos, y las implicaciones de tales marcos para la gestión de los desastres.

Palabras clave: Desastres. Tecnologías de comunicación. Desarrollo. Blumenau.

\section{Introdução}

De acordo com Spence, Lachlan \& Griffin (2007), a comunicação em tempos de crise busca prevenir ou diminuir os resultados negativos de um episódio em concreto e cumpre, sobretudo, duas funções: uma informativa e outra persuasiva. Em primeiro lugar, as mensagens devem criar uma compreensão racional do risco e, depois, incentivar o público a adotar medidas que evitem uma possível ameaça ou atenuem as consequências de tais acontecimentos. A gestão da crise exige planejamento, mobilização e integração do poder público e de instituições privadas, do corpo de agentes voluntários, das comunidades afligidas e da mídia. A informação ou a falta dela pode influenciar de maneira positiva ou negativa todas as fases do desastre. Nesse sentido, a mídia desempenha um papel crítico na comunicação e compreensão das catástrofes (Pantti, Wahljorgessen \& Cottle, 2012).

Os meios de comunicação ganham protagonismo nas tarefas de envolver os diferentes atores, impulsionar as ações de socorro e apoio às vítimas, e gerar confiança entre os atingidos. Tal perspectiva se funda na percepção de uma série de trabalhos precedentes segundo os quais, durante um desastre, a mídia é a mais importante ferramenta de mitigação à disposição das autoridades porque a sua atuação cria a percepção pública sobre os riscos do evento (Miles \& Morse, 2007; Pérez-Lugo, 2001). 
Nesse contexto, o presente estudo soma-se aos esforços anteriores do Grupo de Pesquisa Estudos Midiáticos Regionais, voltados à compreensão do papel da mídia durante os desastres (Reis \& Zucco, 2012; Reis, Zucco \& Darolt, 2013; Reis \& Cardoso, 2014; Cardoso, Darolt \& Reis, 2015; Reis, Mattedi \& Reimondo Barrios, 2017; Reis, Cardoso \& Reimondo Barrios, 2018, entre outros). Para abordar essas preocupações, o trabalho visa analisar a mudança no emprego das tecnologias da informação e comunicação nos desastres na região de Blumenau a partir do 2008. 0 quadro metodológico se constitui, desde uma perspectiva de ordem qualitativa, em uma investigação bibliográfica, adotando um enfoque exploratório e descritivo. Seu objetivo é fornecer indicadores de como tais tecnologias se desenvolveram na última década, tendo em conta que a mudança dos procedimentos técnicos e políticos para a confrontação de tais desastres coincide com as transformações pelas quais as tecnologias da informação e comunicação passaram.

$\mathrm{Na}$ primeira seção deste artigo, se discutem algumas reflexões teóricas sobre o desenvolvimento dos meios de comunicação social como veículos de distribuição de informação nas diversas etapas dos desastres. De igual forma, se apresentam algumas tendências da pesquisa científica sobre o tema nos últimos anos, destacando aspectos relacionados às mídias sociais e à participação pública em situações de desastres. Em seguida, se apresenta um panorama das catástrofes que atingiram o Vale do Itajaí, especificamente em Blumenau, dando ênfase na evolução da mídia na sua cobertura. Finalmente, se discute como as novas ferramentas e tecnologias mudaram a compreensão, resposta e socialização dos desastres. Nas considerações finais, se reflexiona brevemente sobre a transformação identificada no processo comunicativo em situações de vulnerabilidade, decorrentes do fenômeno tecnológico e do efeito da conectividade.

\section{Mídia e desastres}

Segundo Quarantelli (1991), a maioria do que as pessoas sabem sobre desastres é o que aprendem por meio da mídia. Nesse sentido, o papel da mídia em desastres não pode ser entendido apenas como ferramenta para comunicar e descrever o que aconteceu e manter o público informado. Guion, Scammon \& Borders (2007) argumentam que a mídia, além de ser um dos mais importantes veículos para a distribuição de informações sobre determinados riscos e perigos para as pessoas, é utilizada extensivamente durante as diversas fases de uma tragédia. Sobre o assunto, Leitch \& Bohensky (2014) indicam que os meios de comunicação devem também contribuir para a preparação individual e comunitária, ajudar a identificar ameaças potenciais, permitir que as comunidades aproveitem o potencial e experiências locais para se adaptarem diante de crises, desastres e outros desafios, bem como fornecer um fórum para o planejamento da comunidade sobre a reconstrução pós-desastre.

Com o aumento das catástrofes naturais e antropogênicas e o desenvolvimento dos meios de comunicação social nos últimos anos, os pesquisadores da área têm se preocupado em refletir e aprofundar os estudos sobre o tema. Em um estudo recente sobre as tendências e padrões na pesquisa científica sobre mídia e desastres nos últimos 20 anos, Reis, Mattedi \& Reimondo 
Barrios (2017) constatam o expressivo incremento percentual ao longo dos anos 2000 dos estudos realizados sobre mídia e desastres. Diversos trabalhos deram particular atenção às narrativas da cobertura midiática dos desastres. Temas como a religião, a questão racial e a resiliência constituem um ponto de interesse nos relatos produzidos pela mídia. Sonnett, Johnson e Dolan (2015) destacam que na cobertura posterior ao Furação Katrina muitos estudos apresentaram representações racialmente tendenciosas e estereotipadas da população afetada. Por outra parte, McLaughlin (2016) indica que depois dos desastres (terremoto, tsunami e acidente nuclear) de março de 2011 no Japão, a narrativa da mídia concentrou-se em transmitir uma imagem favorável dos ativistas religiosos que forneceram ajuda nas regiões afetadas pelos desastres. Outros estudos centraramse no uso da Internet e das novas mídias para a cobertura jornalística durante os desastres (Laituri \& Kodrich, 2008; Macias, Hilyard \& Freimuth, 2009).

A partir de 2017, estima-se que $78 \%$ dos brasileiros possuem e usam smartphones (IBGE, 2018). A adoção dessa tecnologia proporcionou acesso imediato e sem precedentes as pessoas para o rápido consumo e produção de informações. Comensurável com o aumento da comunicação móvel tem sido um acrescentamento correspondente no uso de mídia social como uma ferramenta para compartilhar notícias e redes. Oitenta por cento do uso de mídia social ocorre via tecnologias móveis, e $58 \%$ dos brasileiros, cerca de 122 milhões de pessoas, usam redes sociais como Facebook, Twitter, YouTube, entre outras (IBGE, 2018). De fato, as mídias sociais estão mudando cada vez mais a forma como a sociedade se comunica antes, durante e depois dos eventos dos desastres, pois estas operam fora dos tradicionais intermediários de informação e ajuda. Informações geradas em sites de mídia social estão rapidamente se tornando novas fontes de dados para auxiliar na tomada de decisões durante eventos climáticos extremos e situações de emergência.

Para Cooper et al (2015), estas mídias sociais representam uma valiosa oportunidade para promover os objetivos da gestão de risco de desastres relacionados com a mitigação, preparação, resposta e recuperação. Porém, deve-se ter em conta que os dispositivos técnicos estabelecem diferenças significativas na dinâmica das atividades, o que indica que relatar o impacto por meio de um tweet é diferente da produção de uma reportagem televisiva (Reis, Mattedi \& Reimondo Barrios, 2017). Laituri \& Kodrich (2008) indicam que a mídia online tem sido particularmente eficaz em facilitar a comunicação interativa de informaçõos relevantes, conectando-se a um público maior que pode participar de forma indireta no desastre.

As mídias sociais abriram visivelmente a discussão sobre a questão da participação pública em desastres e mudaram a maneira como se interage e se responde como sociedade. Por meio das mídias sociais, um número crescente de textos, fotos, vídeos, mapas e outras informações de testemunhas oculares contribui para a informação disponível em torno de eventos de crise. Enquanto isso, as organizações de gerenciamento de emergências estão trabalhando para entender como responder ao novo conteúdo e plataformas de comunicação (Hughes, Palen \& Peterson, 2014). Por exemplo, já desde 2011, alguns pesquisadores alertavam que mais do $45 \%$ dos membros da Associação Internacional de Gerentes de Emergência usavam o Facebook para emergências; e cerca de $43 \%$ usavam o 
Twitter para coletar informações e se comunicar com o público durante emergências.

Sobre o uso de redes sociais durante situações de desastres, precisa-se destacar uma questão importante: a sobrecarga de informações (social information overload). O termo refere-se ao envio/transmissão de muitas informações nas mídias sociais durante emergências, o que torna impossível para os indivíduos encontrar, reconhecer e responder facilmente, muito menos organizar, fazer sentido e agir nessas ocasióes (Hiltz \& Plotnick, 2013). Geralmente, as mensagens recebidas não são suficientemente organizadas por tópico ou conteúdo, o que torna difícil monitorar as situações de crise. Em resposta a este desafio, pesquisadores projetaram e criaram vários sistemas que filtram e analisam fluxos de mídia social em tempos de crise. Dessa forma, se visa aumentar os esforços na compreensão e integração da informação.

O Facebook, por exemplo, ativou em 2014 o "Safety Check", uma ferramenta que objetiva comunicar aos contatos online que um usuário está em segurança. Ela possibilita descobrir se outros usuários também estão em situações de risco. As principais funcionalidades do serviço permitem: a) avisar sobre a segurança de um usuário, que aciona a marcação "Estou a salvo" e uma notificação é enviada pelo feed de notícias; b) verificar se outras pessoas na área do desastre estão seguras; c) marcar amigos, caso eles também estejam em regiões de risco. A ferramenta é acionada se um número suficiente de pessoas na área afetada publicarem sobre um determinado incidente. A rede social verifica a localidade marcada no perfil do usuário e sua última geolocalização - que precisa estar habilitada - usada para acessar a web. O projeto foi inspirado ${ }^{2}$ no desastre nuclear de Fukushima em 2011 no Japão ${ }^{3}$, o qual afetou 12 milhões de pessoas no país e outras 400 mil tiveram que abandonar a área. Durante o estado de emergência, percebeu-se como a população utilizou as redes sociais para se comunicar nesses locais.

A título de exemplo, se pode verificar na Figura 1 como os usuários do Facebook usaram o Safety Check durante os alagamentos que ocorreram em São Paulo em 2016.

\footnotetext{
1 Disponível em: < https://www.facebook.com/about/safetycheck/ >. Acessado em 20 fev. 2017

2 Disponível em: < http://newsroom.fb.com/news/2014/10/introducing-safety-check/>. Acessado em 20 fev. 2017.

3 Disponível em: < http://g1.globo.com/mundo/noticia/2012/07/japao-admite-que-fukushima-foidesastre-provocado-pelo-homem-1.html >. Acessado em 20 fev. 2017.
} 
Figura 1 - Acionamento do Safety Check em São Paulo, Brasil.

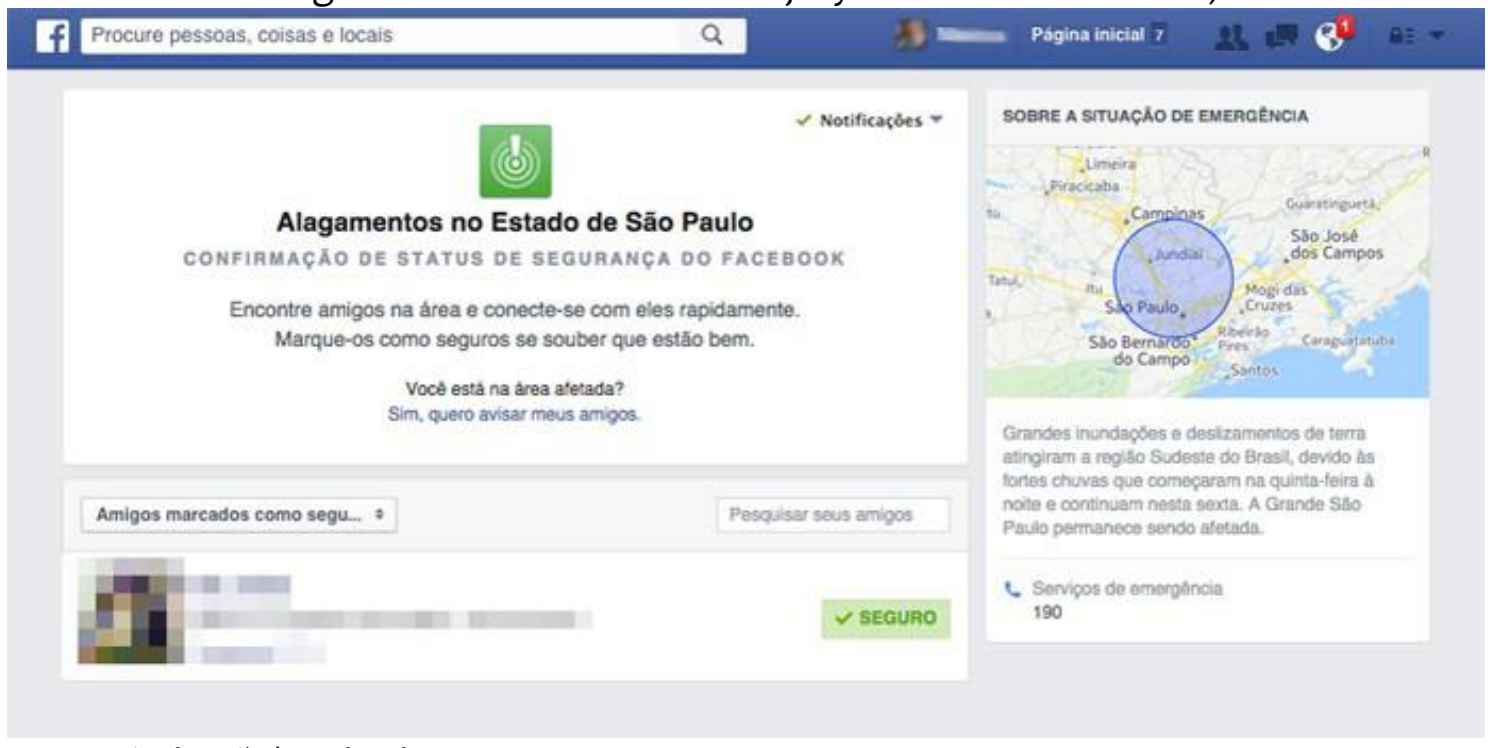

Fonte: Divulgação/Facebook.

Por outro lado, o Twitter lançou em 2013 o "Twitter Alerts"”. Com ele usuários recebem alerta sobre emergências que envolvem a segurança pública, acessibilidade, desastres ambientais e situações em que veículos de comunicação possam ficar inacessíveis. Inicialmente o serviço foi disponibilizado para Estados Unidos, Japão e Coreia do Sul. Posteriormente o recurso chegou ao Brasil, Reino Unido, Irlanda, Austrália, Equador ${ }^{5}$ e outros países ${ }^{6}$. Os usuários podem receber os alertas de todos os países em que o Alerts já está em operação. No caso específico do Brasil, apenas algumas organizações utilizam a ferramenta: o Centro de Operações da Prefeitura do Rio de Janeiro (COR), o Centro Integrado de Comando da Cidade de Porto Alegre e a Prefeitura de Curitiba. Para receber os alertas, basta seguir um dos perfis, e quando a organização emitir um tweet emergencial, ele será marcado com um sino laranja e a hashtag \#alert. Os alertas poderão ser visualizados no feed do Twitter na web e nos aplicativos para mobile via notificações push (na tela de bloqueio do dispositivo). Vale ressaltar que o COR (@OperacoesRio) foi a primeira agência no Brasil a tornar essa funcionalidade disponível para os usuários.

Além disso, existem diferentes iniciativas de instituições intragovernamentais e intergovernamentais em trabalho conjunto para mapear e monitorar os diferentes desastres ambientais que assolam o país. Se destacam entre elas: AlertaRio (http://alertario.rio.rj.gov.br/); Agência Nacional de Águas (ANA - http://www2.ana.gov.br/); Agência Pernambucana de Águas e Clima (APAC http://www.apac.pe.gov.br/); Centro Nacional de Gerenciamento de Riscos e Desastres (CENAD - http://www.mi.gov.br/web/guest/defesa-civil/cenad)); CIAGRO, Companhia de Pesquisa de Recursos Minerais (CPRM - http://www.cprm.gov.br/);

\footnotetext{
${ }^{4}$ Disponível em: <https://blog.twitter.com/2013/twitter-alerts-new-countries-and-features>. Acessado em 20 fev. 2017.

5 Disponível em: <https://exame.abril.com.br/tecnologia/relatorio-destaca-papel-das-redes-sociaisem-terremoto/>. Acessado em 12 mar. 2018.

6 Disponível em: <https://about.twitter.com/pt/products/alerts/participating-organizations>. Acessado em 20 fev. 2017.
} 
Departamento de Controle do Espaço Aéreo (DECEA - https://www.decea.gov.br/); Departamento de Recursos Minerais RJ (DRM/RJ - http://www.drm.rj.gov.br/); Empresa de Pesquisa Agropecuária e Extensão Rural de Santa Catarina (EPAGRI/CIRAM - http://www.ciram.epagri.sc.gov.br/); Fundação Cearense de Meteorologia e Recursos Hídricos (FUNCEME - http://www.funceme.br/); Instituto Geológico (IG - http://igeologico.sp.gov.br/); Instituto Brasileiro de Geografia e Estatística (IBGE - http://www.ibge.gov.br/), entre outros.

É importante mencionar que além das redes sociais, outras tecnologias da informação e comunicação (TICS) contribuem à medição, coleta, análise e divulgação de dados nas diferentes fases do desastre. O rádio, a televisão, sistemas de informação geográfica (SIG) e sensoriamento remoto, aplicativos móveis (apps), telefonia móvel e SMS, sistemas de alerta e rádio amador são algumas das tecnologias que, na gestão dos riscos de desastres, podem ser utilizadas para subsidiar os processos de resposta e reconstrução bem como para mitigar e prevenir o aumento da vulnerabilidade (LUDWIG, 2017).

\section{Mídia e desastres em Blumenau, Brasil}

Blumenau é um município do estado de Santa Catarina na região sul do Brasil. Localiza-se na Mesorregião do Vale do Itajaí e é a cidade-sede da região metropolitana. É a terceira cidade mais populosa do estado ${ }^{7}$, e possui uma área territorial de $518,619 \mathrm{~km}^{2}$. Blumenau conta com um dos maiores índices de desenvolvimento humano do Brasil $(0,806 \text { IDMH })^{8}$ e constitui um dos principais polos industriais, tecnológicos e universitários catarinenses.

A história dos desastres do Vale do Itajaí leva em conta três fatos interligados, de acordo com Frank (1995). O primeiro diz respeito à colonização e à identidade étnica dos seus protagonistas; o segundo ao desenvolvimento socioeconômico, que teve como base a indústria têxtil e o consequente processo de urbanização do território; e por fim, a intensificação da depredação ambiental e a problemática dos desastres. Em relação ao processo histórico, é fato que os colonizadores do Vale do Itajaí foram fundamentais para a abertura da comunicação entre o litoral e o planalto. Contudo, a expansão urbana associada à ocupação de áreas inundáveis e a apropriação das encostas desencadeou um intenso histórico de tragédias, situando em especial Blumenau como um território de vulnerabilidade. Constata-se o crescente número de enchentes a partir de 1910, período que coincide com o princípio do desenvolvimento da colonização em toda bacia hidrográfica. Sobre o assunto, Moura, Frenzel e Moura (2019) apontam que o processo de ocupação e distribuição da população no ambiente urbano está intimamente relacionado com as dinâmicas econômicas.

As inundações são parte da memória da cidade e marcam sua capacidade de superar tragédias e valorizar a cultura local. Com grandes precipitações

7 População estimada de Blumenau: 357.199 pessoas (2019), segundo o IBGE. Fonte: https://www.ibge.gov.br/cidades-e-estados/sc/blumenau.html Acesso: junho, 2020.

8 Blumenau ocupa a $25^{\text {a }}$ posição entre os 5.565 municípios brasileiros segundo o IDHM. Nesse ranking, o maior IDHM é 0,862 (São Caetano do Sul) e o menor é 0,418 (Melgaço). Fonte: http://www.atlasbrasil.org.br/2013/pt/perfil_m/blumenau_sc Acesso: junho, 2020. 
pluviométricas, seu território forma um canal de passagem das águas, o que se torna uma condição incontrolável em épocas de grandes incidências (Reis \& Cardoso, 2014). Com quase todos os morros transformados em residências e a quantidade de chuva superior ao estimado como normal, descem por suas encostas lama que inunda e leva diversas casas, vidas e sonhos. As condições naturais e sociais se unem para formar os desastres, como os observados nas últimas décadas no Vale do Itajaí. Nesse sentido, tais eventos deveriam denominar-se socionaturais ou socioambientais, pois a natureza por si só não os provoca. Sua intensidade está ligada à interferência humana (Mattedi, 2000).

Durante os desastres, os meios de comunicação desempenham um papel fundamental na prestação de serviços. As catástrofes registradas na região, tornaram-se mais dependentes da mídia em relação à forma como elas foram conhecidas, respondidas e socializadas. Dessa forma, são destacados a seguir os desastres que atingiram o Vale do Itajaí, em especial a cidade de Blumenau, dando ênfase na evolução da mídia na cobertura de tais catástrofes.

\section{Período 1980-2008}

Durante anos, o jornal, o rádio e a televisão eram os meios de comunicação que difundiam as mensagens de aviso, dicas de preparação e informações de evacuação para o público antes, durante e depois dos desastres. Nas múltiplas inundações, enchentes, deslizamentos e outros desastres socionaturais de grandes proporções que atingiram Blumenau entre 1980 e 2008, o destaque nas comunicações foi o meio que mais está presente nos lares, o rádio (Reis \& Darolt, 2009). Ele constituiu para muitos moradores a principal fonte de informação durante a catástrofe. Entre as emissoras que realizaram a cobertura informativa no período podem-se citar Rádio Clube, Rádio Blumenau, Rádio Nereu e Rádio União. Seus transmissores localizados em área livre de enchentes e o emprego de geradores de energia próprios lhes permitiram permanecer no ar por vários dias, repassando as informações de utilidade pública.

O trabalho do rádio nessas décadas foi excepcional, apesar do evidente improviso, falta de equipamentos, problemas técnicos, amadorismo e precariedade (Reis \& Darolt, 2009). Mas esses elementos não ofuscaram a sua importância significativa nos momentos trágicos vividos pela sociedade do Vale do Itajaí. A contribuição radiofônica foi um fator importante e estratégico nas informações prestadas à população atingida. O apoio dos radioamadores foi vital, visto que eles formavam cadeia para ajudar às pessoas mais necessitadas. Foi um período em que os ouvintes davam muito valor ao trabalho dos comunicadores, prestigiando as suas emissoras preferidas com uma audiência fiel.

As notícias da televisão também ajudaram a transmitir, ou às vezes criar, uma sensação de expressão nacional. Em trágicos eventos como as enchentes de 1983 e 1984, destacou-se a atuação da RBS TV. A emissora teve o prédio totalmente atingido pelas águas, mas o estúdio foi transferido precariamente para o prédio da Embratel, onde foram feitas as transmissões do Vale do Itajaí para Florianópolis. A Rede Globo abriu sinal para que as informações da catástrofe fossem transmitidas para todo o Brasil e exterior por meio da cadeia da solidariedade, enviando as notícias para a população de forma precária, mas ainda assim, de suma importância durante os acontecimentos (Darolt, Garrote \& Reis, 2011). 
Os trágicos movimentos de massa e enxurrada que devastaram os bairros Glória e Progresso em 1990, atingiram 1.310 casas, das quais 286 foram danificadas e 66 foram totalmente destruídas, deixando 754 pessoas desabrigadas (Bacca, 2000). Este caso, teve uma cobertura especial pelo Jornal de Santa Catarina, que relatou o drama da situação (Figura 2).

Figura 2 - Reportagem do Jornal de Santa Catarina em 1990

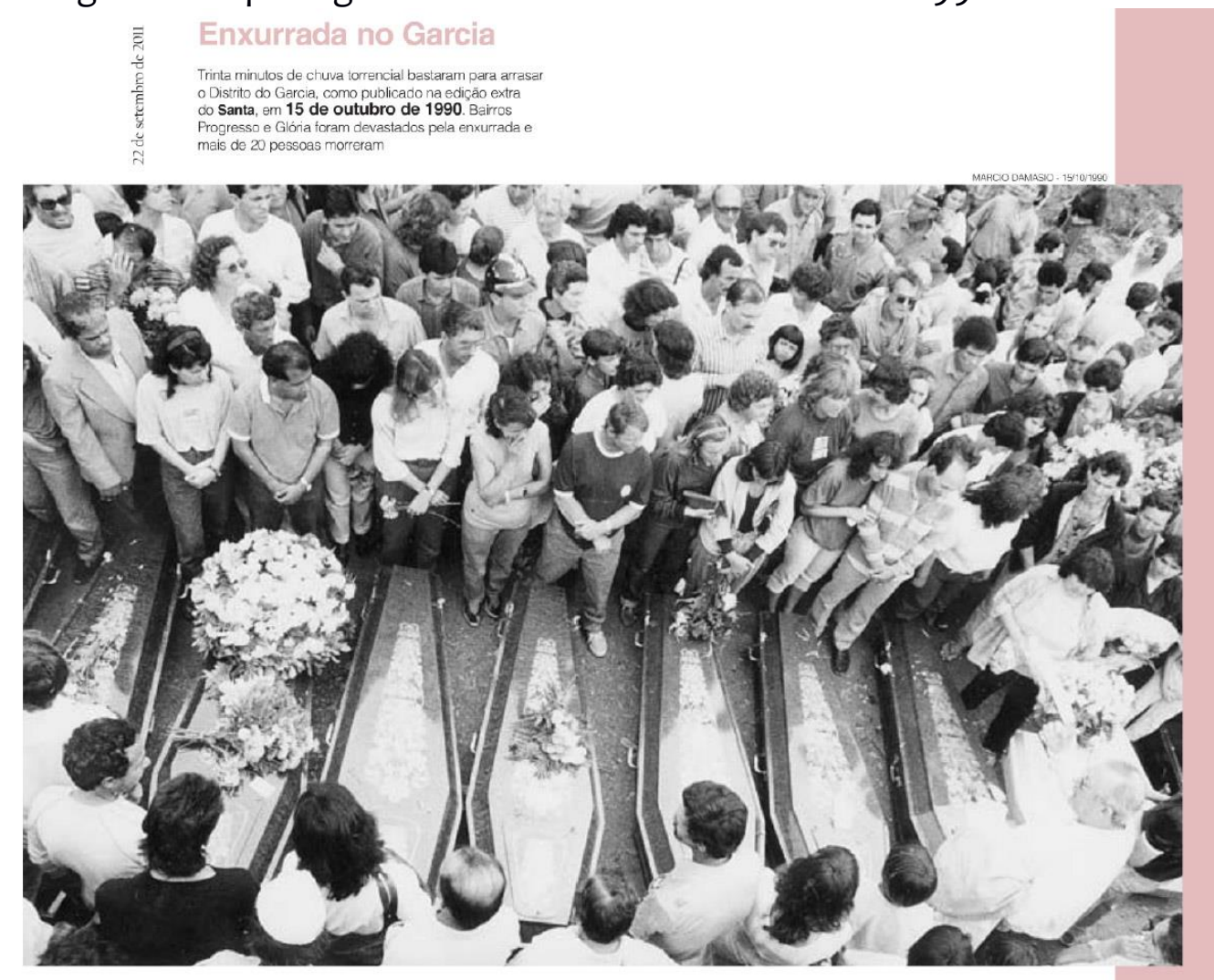

Fonte: Jornal de Santa Catarina, 2011

Estreando na década de 1990, a Internet começou a se tornar uma fonte de informações sobre desastres e notícias relacionadas a emergências. Tais avanços tecnológicos permitiram à população de Blumenau o acesso às informações de uma maneira mais abrangente que nas enchentes anteriores. As notícias se propagaram pela web em portais como Terra, G1, UOL, Folha de S. Paulo e Estado de S. Paulo, os quais replicaram as informações produzidas pelo Jornal de Santa Catarina com a finalidade de fazer ecoar na rede mundial de computadores os acontecimentos que assolavam a cidade.

Outro diferencial tecnológico foi a telefonia móvel, que permitia a transmissão de dados através de SMS (sigla em inglês para Short Message Service). Vale destacar que essa modalidade surgiu entre 1999 e 2000. Antes dessa data os aparelhos não tinham a capacidade de enviar nem receber pacotes de dados. Neste sentido, muitos atingidos fizeram uso desse recurso para se comunicar durante as catástrofes. No passado, os telefones de linhas fixas eram distantes uns dos outros e não eram acessíveis para todos, pelo alto custo para sua aquisição e dependiam do cabeamento da rede para funcionar. 
No desastre socioambiental de 2008, a cobertura do rádio teve destaque novamente. O acompanhamento jornalístico da Rádio Nereu Ramos proporcionava boletins dos acontecimentos e a população utilizou este meio para buscar notícias, pedir ajuda e socorro da Defesa Civil. A maior dificuldade nas transmissões foi a falta de eletricidade. Diversos cabos da rede foram danificados, impossibilitando a chegada de energia nas localidades. Além das rádios AM, a cobertura informativa do desastre de 2008 foi diferenciada das outras enchentes na mídia local. A FURB-FM (emissora universitária) foi o canal de comunicação que ficou durante todo o período no ar retransmitindo também a programação das emissoras FURB-TV, TV Galega e TV Legislativa. O tempo que as demais permaneceram transmitindo variou consideravelmente. Algumas conseguiram manter-se por mais tempo no ar, outras não tiveram êxito (Darolt \& Reis, 2010).

Período 2008-2018

Em 2008, após meses de chuvas contínuas que saturaram o solo, a cidade de Blumenau foi submetida a uma tragédia sem precedentes. Os deslizamentos, acelerados pelas condições existentes (vales íngremes, solo argiloso, ocupação irregular de áreas de risco, remoção da vegetação protetora e falta de drenagem), constituíram um novo fenômeno na história dos desastres do Vale do Itajaí. Essa catástrofe foi o primeiro acontecimento grave no Brasil na era da Internet (Global Voices, 2009). Para a imprensa foi complexo analisar a situação que estava ocorrendo e passar informações para a população sobre a proporção dos acontecimentos. Dessa forma, e com a ajuda das novas ferramentas e tecnologias de comunicação, a audiência até então passiva tornou-se um participante ativo na criação e disseminação de notícias sobre o desastre. Redes sociais como Twitter, Facebook, YouTube e alguns blogs permitiram à população procurar e distribuir informação em tempo real que a mídia tradicional não podia oferecer.

No Twitter, os usuários relatavam o que viam pela janela. Voluntários e vítimas usaram o canal \#blumenau para a troca de mensagens e para saber das últimas notícias (Reis \& Zaboenco, 2010). No Orkut, os internautas postavam fotografias, mapas das estradas bloqueadas e organizavam fóruns para discussão que abordavam diferentes temáticas: estabelecimentos que aumentaram o preço das mercadorias de forma abusiva, toque de recolher, postos de coleta de doações, ou pequenos vídeos e questionamentos sobre o aumento do valor do saque do FGTS para as vítimas, entre outros assuntos (Reis \& Zaboenco, 2010). No caso de YouTube, por ser o principal destino dos internautas para compartilhar vídeos, foi de suma importância para a divulgação de imagens da tragédia. Os usuários do serviço contribuíram para a formação dos conteúdos que foram publicados nas outras redes virtuais, servindo diretamente como fonte de informação.

Um dos primeiros meios a relatar os incidentes de 2008 foi um blog, o Notícias de Blumenau, conhecido como Alles Blau. O espaço foi mais ágil na cobertura que a mídia tradicional, trazendo a notícia antes de qualquer outro meio de comunicação. O blog surgiu para reunir as informações que estavam dispersas na rede: o que se publicava no Twitter, o que se debatia no Orkut, o que se via no YouTube, e o que as emissoras de rádio transmitiam, especialmente quando a crise ganhou contornos dramáticos. Por vários dias o blog foi quem deu notícias sobre a situação de Blumenau para quem não estava na região, já que as grandes 
corporações midiáticas acompanhavam o assunto com relativa distância. Quando a popularidade do Alles Blau se espalhou pela rede, os internautas passaram a enviar fotos e relatos diretamente para o blog, que se tornou fonte de consulta (Reis \& Darolt, 2009).

O ano de 2010 constitui um marco para a cobertura do Jornal de Santa Catarina no que se refere à incorporação de novas tecnologias. Ao explorar seu site (www.santa.com.br) e utilizar hyperlinks, vídeos, galeria de fotos, infográficos, atualizações em tempo real, blogs e redes sociais virtuais, o veículo criou um novo paradigma para a cobertura de enchentes no Vale do Itajaí, possibilitando uma maior aproximação ao leitor, que teve a oportunidade de comentar e participar das publicações. Tais ferramentas deram mobilidade e agilidade na distribuição das informações, o que permitiu romper os limites de tempo e espaço na cobertura jornalística.

Em setembro de 2011, as cheias do Rio Itajaí Açu marcaram mais uma vez. A população, as autoridades e os veículos de comunicação já estavam familiarizados com a utilização das mídias digitais e souberam tirar proveito delas para cumprir o papel quando os meios tradicionais não conseguiam operar.

As informações veiculadas pelo "Santa" foram importantes para a população, como é o caso das notícias sobre abastecimento de água potável e de energia elétrica nas diferentes regiões. Além de fonte de informação, o jornal também buscava ser o porta-voz das diversas autoridades (prefeito, governador e presidente da república) e a finalidade era repassar as ações que estavam sendo tomadas para amenizar os efeitos do fenômeno climático na comunidade. Nessa mesma linha, profissionais e técnicos (secretários de Obras, da Defesa Civil, meteorologistas), e estudiosos de diferentes áreas também tiveram suas orientações retransmitidas para orientar a população sobre como proceder naquela situação. Esses procedimentos foram usados também nas enchentes de 2013 e 2014, que colocaram a região em alerta e alguns municípios em situação de emergência.

As inundações de 2015 foram marcadas pela implementação de uma ferramenta digital associada ao mobile. Um aplicativo que mudaria a forma de conexão entre os usuários no país, chamado WhatsApp. O app criado em 2009 por Jan Koum e Brian Acton ${ }^{9}$ foi adquirido em 2014 pelo Facebook, mas teve sua ascensão no Brasil em 2015, e atualmente lidera a preferência dos brasileiros ${ }^{10}$. Ele está presente em mais de 180 países, reunindo aproximadamente 1 bilhão usuários. O serviço começou como uma alternativa ao sistema de SMS, e atualmente oferece suporte ao envio e recebimento de uma variedade de arquivos de mídia, tais como: fotos, vídeos, documentos, compartilhamento de geolocalização, textos, áudio e chamadas de voz. Esse conjunto de facilidade foi absorvido pelos usuários mudando as práticas e processos comunicacionais.

O WhatsApp foi o grande diferencial no desastre de 2015, porém seus usuários, além de emitir informações, também ficaram expostos a proliferação de

9 Disponível em: < https://www.whatsapp.com/about/>. Acessado em 01 abr. 2017.

10 Disponível em: < http://idgnow.com.br/mobilidade/2017/03/06/whatsapp-e-o-aplicativo-maisbaixado-pelos-brasileiros-na-google-play/>. Acessado em 01 abr. 2017. 
boatos $^{11}$, por não perceberem quando uma notícia era factual ou não, desconhecendo as fontes dos dados. Nessa linha de raciocínio, existiu também o compartilhamento de "má-fé", que tem a finalidade de desacreditar a imagem de alguém publicamente, evocando muitas vezes a comoção política das pessoas como fator motivador da viralização. A alta conexão nesse desastre desencadeou mais caos entre a comunidade do que benefícios.

No mesmo ano 2015, a Prefeitura de Blumenau desenvolveu por meio da Diretoria de Sistemas da Secretaria Municipal de Gestão Governamental o aplicativo AlertaBlu $^{12}$. Ele oferece informações e serviços para a comunidade em casos de previsões de fortes chuvas, enchentes, enxurradas, deslizamentos e situações emergenciais no trânsito para auxiliar motoristas. Além disso, o aplicativo permite aos usuários acompanhar o nível do Rio Itajaí-Açu, a cota de alagamento das ruas, e proporciona uma lista de abrigos ativados em situações de emergência, bem como telefones úteis (Bombeiros, Defesa Civil e Polícia Militar). De maneira geral, as cheias de 2015 e 2017 foram marcadas pelos aplicativos e a instantaneidade dos fatos e notícias pulsando na palma da mão dos usuários. Com isso, passou-se a ter um desencontro de informações por conta da possibilidade de todos poderem produzir e distribuir conteúdo.

\section{Sobrecarga de informação}

O mundo tem sido espectador de rápidas transformações, e as mudanças têm se tornado constantes. Segundo Kovach \& Rosenstiel (2001), cada vez que houve um período de mudanças significativas, sociais, econômicas e/ou tecnológicas, ocorreu uma transformação nas notícias. Isso aconteceu nos anos 1830-1840 com o advento do telégrafo; na década de 1920 com o rádio; e na década de 1950 com a televisão. A chegada da Internet, seguida pelas tecnologias móveis e redes sociais, trouxe a mais recente e dramática mudança nas notícias. Dentro deste contexto, os processos de comunicação em tempos de crise também foram impactados e modificados. Tweets em tempo real, vídeos amadores no YouTube e perfis privados no Facebook preencheram o "vácuo de notícias" que até alguns anos atrás caracterizava a cobertura de grandes eventos de crise (Bruno, 2011).

Como ponto de partida, e para entender melhor o impacto da mudança no emprego das novas tecnologias de informação e comunicação nos desastres de Blumenau nos últimos dez anos, se faz necessário abordar as seguintes questões: Como as novas mídias e tecnologias alteraram a cobertura dos desastres entre 2008 e 2018? Em que medida o conteúdo gerado pelos usuários substituiu as formas de comunicação da mídia tradicional nas situações de emergência?

Para responder a essas perguntas, parte-se do pressuposto de que as novas ferramentas e tecnologias mudaram profundamente a compreensão, resposta e socialização das catástrofes em dois aspectos principais: (1) como os desastres são enquadrados na cobertura de notícias da mídia e (2) quem relata tais acontecimentos. Sobre o primeiro elemento, passa-se de indivíduos que consumiam

11 Disponível em: <http://dc.clicrbs.com.br/sc/noticias/noticia/2015/10/pancho-enchente-de-boatosnao-multiplique-informacoes-duvidosas-4885502.html?pagina=35>. Acessado em: 12 mar. 2018. 12 Disponível em: < http://alertablu.cob.sc.gov.br/p/detalhada>. Acessado em 20 fev. 2017 
as informações em um contexto de isolamento para outro modelo, no qual a audiência está integrada por conta do ambiente em rede. Quanto mais rápido o contexto tecnológico se altera, maior é a velocidade na mudança do paradigma comunicacional, que passa da escassez de informações para a abundância de dados.

Como visto anteriormente, no período de 1980-2008, a cobertura de notícias dos desastres da região dependia geralmente das fontes oficiais e se concentrava na mídia tradicional (jornal, rádio e TV). No entanto, na última década, o desenvolvimento e expansão das novas mídias e ferramentas tem alterado o fluxo da comunicação, debilitando as fontes oficiais tradicionais e, consequentemente, substituindo o modelo comunicativo vertical-centralizado, usado pelo governo, gerentes de emergência e a mídia tradicional. Por outra parte, o enquadramento noticioso do desastre adquire uma escala maior em termos de alcance global graças às novas mídias. Elas oferecem oportunidades para testemunhar o impacto das catástrofes em todo o mundo (Cottle, 2013). Dessa forma, depois do 2008, redes sociais e outros recursos da Internet comunicaram imagens e informações ao resto do país a respeito dos acontecimentos que atingiam Blumenau. Essas ferramentas mobilizaram pessoas, agregaram informações, criaram campanhas e protagonizaram a linha de frente de apoio que Santa Catarina recebeu (Reis \& Zaboenco, 2010).

A cobertura midiática dos desastres se viu afetada também pela velocidade acelerada e instantaneidade demonstrada pelas redes sociais virtuais. Embora os benefícios do uso de mídias sociais durante os desastres estejam bem documentados, a informação em tempo real atingiu um ponto em que o imediatismo substituiu as práticas tradicionais de análise e gerenciamento de informação. Assim, essa velocidade, agravada pela quantidade, pode encobrir a imagem da situação, tornando difícil para os gestores tomar decisões precisas e oportunas (Hughes, Palen \& Peterson, 2014). Esse foi o caso das enchentes de Blumenau posteriores a 2008, quando o aumento dos boatos nas redes sociais e aplicativos de comunicação instantânea disseminaram um verdadeiro pânico digital entre os usuários. A isto somou-se uma crescente erosão na confiança dos usuários em relação às instituições públicas, que eram os pilares de onde partia a comunicação oficial.

Isso leva ao segundo aspecto da mudança, e que está relacionado a quem relata tais acontecimentos. Sobre o assunto, Bowman \& Willis (2003) explicam que:

A venerável profissão do jornalismo se encontra em um momento raro na história, onde, pela primeira vez, sua hegemonia como portadora das notícias está ameaçada por não apenas novas tecnologias e concorrentes, mas, potencialmente, pela audiência que serve (Bowman \& Willis, 2003, p.7).

Enquanto as organizações de gerenciamento de emergência começaram a considerar como incluir as mídias sociais em suas atividades de comunicação, o discurso em torno da participação pública na crise começou a mudar. Anteriormente, os canais de comunicação pública eram caminhos de mão única que fluíam de organizações de resposta a emergências para membros do público (Palen \& Liu, 2007). No entanto, com o surgimento de aplicativos digitais e redes sociais, as audiências ganharam maiores oportunidades de participação no processo de 
criação, consumo e distribuição da notícia. Dessa forma, "a natureza participativa da cobertura de notícias apagou a linha entre os afetados pelas notícias e os que cobrem as notícias" (Haddow \& Haddow, 2008).

Munidos de smartphones em mãos, os usuários de redes sociais tornam-se potenciais comunicadores em situações de desastres. Ruídos comunicacionais, no entanto, se colocam para dificultar a propagação entre emissores e receptores. Deve-se ter em conta que quem comunica, subjuga as consequências das suas ações, e aquele que compartilha o equívoco é cúmplice com o ato, gerando um sentimento de pânico no meio digital. Na última década, Blumenau tem sido testemunha de tais situações.

As mídias sociais oferecem múltiplos recursos de apoio que podem reduzir o risco durante as crises, e os indivíduos precisam confiar nelas como uma fonte de informação necessária para tomar decisões críticas de segurança. 0 empoderamento cidadão e seu envolvimento no jornalismo participativo e nos esforços formais de resposta a emergências levantam questões sobre credibilidade, confiança e responsabilidade. Esses três aspectos tornam-se fatores definidores e permanentes na cobertura jornalística de desastres. A abordagem de "tweetar primeiro e verificar depois" demonstra a transformação que afetou a cobertura informativa. Esta estratégia se contrapõe a uma das regras de ouro do jornalismo: cada notícia deve ser verificada antes da publicação (Bruno, 2011).

Tanto o conteúdo quanto a fonte desempenham papéis importantes na maneira como a informação é percebida. Conhecimento valioso pode aparecer de qualquer lugar, e nos dias de hoje, está sendo gerado pela audiência por meio das redes sociais. Nesse contexto, a revolução tecnológica que conectou a maioria dos usuários, criou de certa forma uma escassez de credibilidade, de confiança e de capacidade profissional para lidar com a nova realidade da comunicação.

Não é apenas o número de fontes que está crescendo, mas também a quantidade de informações. A sobrecarga de informação continua sendo uma barreira para o uso efetivo das mídias sociais durante desastres (Hiltz \& Plotnick, 2013). Frequentemente, isso gera grandes volumes de conteúdo que não estão totalmente relacionados com a situação específica, não são direcionados aos gestores de emergência ou estão simplesmente desatualizados. Agências e organizações que buscam efetivamente usar estratégias de gerenciamento de desastres online devem, portanto, considerar métodos mais eficazes para lidar com a sobrecarga de informações. A mesma ferramenta que transformou o paradigma comunicacional - da informação de menos para a informação demais - é a chave para restabelecer a confiança e a credibilidade da mídia, por meio da promoção da educação tecnológica dos usuários.

No quadro abaixo, se apresenta o desenvolvimento dos meios de comunicação e tecnologias entre as décadas de 1980 a 2018 em Blumenau. Dessa forma, é possível contextualizar as transformações pelas quais as tecnologias da comunicação passaram, e que coincidem com os veículos que Blumenau utilizou para difundir informações sobre a preparação, resposta e recuperação dos desastres que afetaram à região. 
Quadro 2 - Meios de comunicação disponíveis nas décadas de 1980 a 2018

\begin{tabular}{|c|c|c|}
\hline $\mathbf{1 9 8 0}$ & $\mathbf{2 0 0 0}$ & $\mathbf{2 0 1 8}$ \\
\hline Jornal & Jornal & Jornal \\
Rádio & Rádio & Rádio \\
Televisão & Televisão & Televisão \\
& Internet & Internet \\
& & Blog \\
& & Redes Sociais \\
& & Aplicativos \\
\hline
\end{tabular}

Fonte: Elaborado pelos autores

Tal quadro fornece pistas sobre o papel que jornais impressos, emissoras de rádio e de televisão, internet redes sociais virtuais e aplicativos móveis exerceram na construção da percepção pública dos riscos associados às calamidades. Do mesmo modo, suscita uma análise sobre as implicações de tais enquadramentos para a gestão dos desastres. Com base no caso analisado, se sugere que essa névoa de ambiguidade e sobrecarga gerada pelas novas mídias e redes sociais durante desastres seja resolvida antes de poder ser razoavelmente considerada como uma ferramenta de comunicação confiável para tomar decisões operacionais.

\section{Considerações finais}

O foco central deste trabalho foi analisar a mudança no emprego das tecnologias da comunicação nos desastres de Blumenau a partir do 2008. Para alcançar tal objetivo, inicialmente se forneceram indicações de como tais tecnologias se desenvolveram nas últimas décadas (1980-2018) nas situações de emergência que atingiram o município, tendo em conta que a mudança dos procedimentos técnicos e políticos para a confrontação de desastres, coincide com as transformações pelas quais as tecnologias da comunicação passaram. Posteriormente, se realizou uma reflexão sobre a transformação identificada no processo comunicativo em situações de vulnerabilidade, decorrentes do fenômeno tecnológico e do efeito da conectividade.

Em termos gerais, pode-se concluir que não é apenas o número de fontes que cresceu, mas também a quantidade de informações. Se os aplicativos e plataformas digitais permitiram, por um lado, que o público se sentisse próximo de fatos, notícias e alertas durante os desastres socioambientais que afetaram à região, por outro, essa facilidade de acesso teve uma forte influência na criação e distribuição das notícias e informações. A natureza democrática da tecnologia provocou uma crise de confiança nos interlocutores que habitualmente prestavam informação em estados de emergência. As redes sociais geraram um fetiche pelos amadores, minaram a confiança em especialistas, nos criadores de conteúdo, nos profissionais diplomados e analistas outrora reconhecidos pela audiência. Assim, se sobrecarga de informação pode ser uma barreira para o uso efetivo das mídias sociais durante desastres, a gestão dessa realidade torna-se fundamental.

Neste cenário de rápido movimento, uma questão permanece sem resposta: como o esforço de voluntários digitais pode se aliar eficazmente à iniciativa de gestores de emergência e a mídia tradicional durante situações de desastres? Tal 
situação exige um novo olhar sobre a forma como se cria, consome e distribui a informação na resposta a emergências. O acompanhamento contínuo do desenvolvimento das tecnologias e ferramentas de comunicação vai permitir diagnosticar em que medida, tais mudanças afetam a relação mídia e desastres.

\section{REFERÊNCIAS}

BACCA. L.E. Considerações e opiniões sobre a questão ambiental: o caso de Blumenau, SC. Dynamics: Revista tecno-científica, v.8, n.33, p. 36-56, 2000.

BOWMAN, S.; WILLIS, C. We media. How audiences are shaping the future of news and information. California: The Media Center at the American Press Institute, 2013.

BRUNO, N. Tweet first, verify later? How real-time information is changing the coverage of worldwide crisis events. Reuters Institute for the study of Journalism. Oxford: University of Oxford, 2011.

CARDOSO, M., DAROLT, E. \& REIS, C. Mídia e Desastres Socioambientais: os Meios de Comunicação nas Enchentes do Vale do Itajaí (SC) de 1983 à 2011. In: $7^{\circ}$ Encontro Nacional da Anppas, 2015, Brasília (DF), v. 1, p. 1-13, 2015.

COOPER, G.P. et al. Twitter as a potential disaster risk reduction tool. Part I: Introduction, terminology, research and operational applications. PLOS Currents Disasters, v.7, p. 1-19, 2015.

COTTLE, S. Environmental Conflict in a Global, Media Age: Beyond Dualisms. In: LESTER, L.; HUTCHINS, B. (Eds.) Environmental conflict and the media publisher. New York: Peter Lang Publishing, 2013.

DAROLT, E.; GARROTE, M.; REIS, C. As vozes de uma catástrofe: o relato dos comunicadores das emissoras de rádio AM durante as enchentes da década de 1980 e do desastre sócio ambiental de 2008 em Blumenau (SC). In: KLOCKNER, L. PRATA, N. (Org.) Mídia sonora em 4 Dimensões. História da mídia sonora, EDIPUCRS, Porto Alegre, 27-41, 2011.

\section{DAROLT, E.; REIS C. A participação dos ouvintes na geração de informação no}

rádio: Enchentes da década de 1980 e novembro de 2008 em Blumenau, a partir da percepção dos profissionais do meio. Novo Hamburgo: XI Congresso de Ciências da Comunicação na Região Sul, 2010.

FRANK, B. Uma abordagem para o gerenciamento ambiental a Bacia Hidrográfica do Rio Itajaí, com ênfase no problema das enchentes. Tese de Doutorado.

Florianópolis, 1995. 
GLOBAL VOICES. Cheias no Brasil: blogueiros formam redes de solidariedade. Recuperado de: http://pt.globalvoicesonline.org/2008/11/30/cheias-no-brasilblogueiros-formam-redes-desolidariedade/, 2009.

GUION, D.; SCAMMON, D.L.; BORDERS, A.L. Weathering the storm: A social marketing perspective on disaster preparedness and response with lessons from hurricane Katrina. Journal of Public Policy \& Marketing, v.26, n.1, p. 20-32, 2007.

HADDOW, G.; HADDOW, K.S. Disaster communications in a changing media world. Oxford: Butterworth-Heinemann, 2008.

HILTZ, S.R.; PLOTNICK, L. Dealing with information overload when using social media for emergency management: emerging solutions. In: HILTZ et al (Org). Information overload when using social media. Proceedings of the 10th International ISCRAM Conference - Baden-Baden, Germany, 2013.

HUGHES, A.; PALEN, L.; PETERSON, S. Social media and emergency management. In: TRAINOR, J.; SUBBIO, T. (Ed.) Critical Issues in Disaster Science and Management: a dialogue between researchers and practitioners, p. 349-381, 2014.

INSTITUTO BRASILEIRO DE GEOGRAFIA E ESTATÍSTICA (IBGE). PNAD Contínua TIC 2017: Internet chega a três em cada quatro domicílios do país, 2018. Recuperado de: https://agenciadenoticias.ibge.gov.br/agencia-sala-de-imprensa/2013-agencia-denoticias/releases/23445-pnad-continua-tic-2017-internet-chega-a-tres-em-cadaquatro-domicilios-do-pais.

KOVACH, B.; ROSENSTIEL, T. The elements of journalism: what news-people should know and the public should expect. NewYork: Three Rivers Press, 2001.

LAITURI, M.; KODRICH, K. On Line Disaster Response Community: People as Sensors of High Magnitude Disasters Using Internet GIS. Sensors, n. 8, 2008. LEITCH, A.; BOHENSKY, E. Return to 'a new normal': Discourses of resilience to natural disasters in Australian newspapers 2006-2010. Global Environmental Change, v. 26, p. 14-26, 2014.

LUDWIG, L. As tecnologias da informação e comunicação (TICs) na gestão dos riscos de desastres: o caso do AlertaBlu em Blumenau/SC. Dissertação. Programa de pósgraduação em Desenvolvimento Regional (PPGDR), Universidade Regional de Blumenau (FURB), 2017.

MACIAS, W.; HILYARD, K.; FREIMUTH, V. Blog functions as risk and crisis communication during Hurricane Katrina. Journal of Computer-Mediated Communication, v. 15, p. 1-31, 2009.

MATTEDI, M.A. Subsídios para a análise das relações da sociedade: Natureza no Vale do Itajaí. In: THEIS, I. M.; MATTEDI, M. A.; TOMIO, F. R. L. (Org.). Nosso passado (in) comum. Contribuições para o debate sobre a história e a historiografia de Blumenau. Blumenau: Edifurb/Ed. Cultura em Movimento, 215-241, 2000. 
MCLAUGHLIN, L. Hard lessons learned. Tracking changes in media presentations of religion and religious aid mobilization after the 1995 and 2011 disasters in Japan. Asian Ethnology, v.75, n.1, 2016.

MILES, B.; MORSE, S. The role of news media in natural disaster risk and recovery. Ecological Economics, v. 63, n.2-3, p. 365-373, 2007.

MOURA, E.N.; FRENZEL, A.S; MOURA, I.I. Inundações no Meio Urbano e Vulnerabilidade Social: estudo de caso em Curitiba, Brasil. Redes (Santa Cruz do Sul. Online), v. 24, n. 2, 2019.

PALEN, L.; LIU, S.B. Citizen Communications in Crisis: Anticipating a Future of ICTsupported Public Participation. In: Proceedings of the 2007 Conference on Human Factors in Computing Systems (CHI 2007), New York, ACM Press, 727-736, 2007.

PANTTII, M.; WAHL-JORGESSEN, K.; COTTLE, S. Disasters and the media. New York: Peter Lang Publishing, 2012.

PÉREZ-LUGO, M. The mass media and disaster awareness in Puerto Rico. A case study of the floods in Barrio Tortugo. Organization Environment, v.14, n.1, p.55-73, 2001.

QUARANTELLI, E. Lessons from research: findings on mass communication system behavior in the pre, trans, and postimpact periods of disasters. Newark, NJ: Disaster Research Center, University of Delaware, 1991.

REIS, C.; CARDOSO, M. O histórico papel do Jornal de Santa Catarina na cobertura das enchentes do Vale do Itajaí. In: Encontro regional sul de história da mídia, Florianópolis/Brasil, 2014.

REIS, C.; DAROLT, E. A contribuição da internet para a cobertura das emissoras de rádio de Blumenau/SC durante o desastre socioambiental de 2008: uma análise a partir da percepção dos profissionais do meio. Linguagens - Revista de Letras, Artes e Comunicação, v.3, n.3, p. 313-324, 2009.

REIS, C.; MATTEDI, M.A.; REIMONDO BARRIOS, Y. Mídia e desastres: panorama da produção científica internacional de 1996 a 2016. Intercom: Revista Brasileira de Ciências da Comunicação, v. 40, n.2, p. 77-92, 2017.

REIS, C.; ZABOENCO, G. A. O relato do desastre socioambiental de novembro de 2008 em Blumenau (SC) nas redes sociais da internet. V Encontro Nacional da ANPPAS. Florianópolis, 2010.

REIS, C.; ZUCCO, F. D. The relationship between the crisis committee and the media during the disaster of November 2008 in Blumenau (SC): Implications for dialogue 
with the community. In: BRASIL-USA MASS COMMUNICATION CONFERENCE, Chicago/USA, 2012.

REIS, C.; ZUCCO, F. D.; DAROLT, E. La comunicación del ayuntamiento de Blumenau (Brasil) durante el desastre natural de noviembre de 2008: El reto de la planificación a largo plazo. Anuario Estudios en Comunicación Social Disertaciones, v.6, n.1, p. 86-105, 2013.

SONNETT, J.; JOHNSON, K.; DOLAN, M. Priming implicit racism in television news: visual and verbal limitations on diversity. Sociological Forum, v.30, n.2, 2015.

SPENCE, P.R.; LACHLAN, K.A.; GRIFFIN, D.R. Crisis communication, race, and natural disasters. Journal of Black Studies, v.37, p. 539-562, 2007.

Clóvis Reis. Doutor em Comunicação pela Universidade de Navarra, Espanha. Professor do Programa de Pós-Graduação em Desenvolvimento Regional da Universidade Regional de Blumenau / FURB (PPGDR-FURB) e do Departamento de Comunicação da FURB. Coordenador do Grupo de Pesquisa Estudos Midiáticos Regionais. E-mail: professorclovisreis@gmail.com

Moisés Cardoso. Doutor em Comunicação e Linguagens pela Universidade Tuiuti do Paraná (PPGCOM/UTP). Professor do Departamento de Comunicação da Universidade Regional de Blumenau (FURB). Integrante do Grupo de Pesquisa Estudos Midiáticos Regionais. E-mail: beiocardoso@gmail.com

Yanet M. Reimondo Barrios. Doutoranda em Desenvolvimento Regional na Universidade Regional de Blumenau (PPGDR-FURB). Mestre em Desenvolvimento Regional (FURB). Bolsista CAPES. Integrante do Grupo de Pesquisa Estudos Midiáticos Regionais. E-mail: yanet.barrios89@gmail.com

\section{CONTRIBUIÇÃO DE CADA AUTOR}

a. Fundamentação teórico-conceitual e problematização: Clóvis Reis; Moisés Cardoso; Yanet M. Reimondo Barrios

b. Pesquisa de dados e análise: Clóvis Reis; Moisés Cardoso; Yanet M. Reimondo Barrios

c. Elaboração de figuras e tabelas: Clóvis Reis; Moisés Cardoso; Yanet M. Reimondo Barrios

d. Elaboração e redação do texto: Clóvis Reis; Moisés Cardoso; Yanet M. Reimondo Barrios

e. Seleção das referências bibliográficas: Clóvis Reis; Moisés Cardoso; Yanet M. Reimondo Barrios

Fontes de financiamento: CAPES e FAPESC 